\title{
The long-term earnings consequences of general vs. specific training of the unemployed
}

\author{
Anders Stenberg ${ }^{1,2,3^{*}}$ and Olle Westerlund ${ }^{4,5}$
}

\footnotetext{
* Correspondence: anders. stenberg@sofi.su.se

${ }^{1}$ SOFI, Stockholm University, SE-10691 Stockholm, Sweden ${ }^{2}$ Linneaus University, Växjö/Kalmar, Sweden

Full list of author information is available at the end of the article
}

\begin{abstract}
Training programs for the unemployed typically involve training specific skills in demand amongst employers. In 1997, Swedish unemployed could also choose general schooling at the upper secondary level. This offers a unique opportunity to assess the theoretically ambiguous long-term relative earnings of general vs. specific training for unemployed. Analyzing detailed administrative data 1990-2010, we find 1) that specific training is associated with higher earnings in the short run, 2) that earnings converge 5-7 years post program and 3) that individuals act on their comparative advantages. When we extrapolate our estimates to life-time earnings, there is overall a relative advantage of specific training. However, for females with limited prior education, we find a relative life-time earnings advantage of general training.

JEL-codes: 121, J62, J68

Keywords: Active labor market programs, Adult education, Vocational training, Earnings
\end{abstract}

\section{Introduction}

Governments in most OECD countries offer training programs for the unemployed, typically oriented toward vocational/specific skills. The consensus view seems to be that vocational/specific training is a more efficient measure for unemployed individuals than are courses providing general/theoretical skills. In the short run, learning a branch specific skill is presumed to better enhance re-entry into employment. General training, without an obvious connection to a labor market branch, may have less of an impact. However, in the long run, if general skills increase the ability to learn new tasks, this could make workers less sensitive to changes in the demand for skills. Earlier studies of adults in general education have reported average earnings returns which still increase eight to ten years after enrolment (Jacobson et al. 2003, 2005, Stenberg 2011). As program effects vary between individuals and over time, these estimates are not directly comparable with evaluations of vocational training programs, but they raise the question of whether the long-term effects of general training would catch up with or exceed the earnings effects of specific training. ${ }^{1}$ In addition, an expansion of the menu of programs could also potentially enhance efficiency by allowing individuals to act on their comparative advantages. Some economists have suggested that 
governments should stimulate adults to enroll in formal schooling during economic downturns (e.g., Heckman and Urzua 2008, Pissarides 2011), but there is an almost complete lack of empirical research on this topic. It is therefore unclear whether skill adjustments among the unemployed should involve a larger element of general training. ${ }^{2}$

The purpose of this article is to evaluate the relative earnings association of general versus specific training for the unemployed. In the spring of 1997, the Swedish government announced the Adult Education Initiative (AEI henceforth) which targeted the same groups of the unemployed as did the traditional vocational/specific training program. AEI enabled unemployed adults aged 25-55 to attend a year of full-time schooling at the upper secondary level, with financial support equal to a maintenance of unemployment benefits. The AEI started in August 1997 and attracted large numbers. We study a sample comprising the unemployed individuals in the spring of 1997. Of these, many individuals enrolled in either the AEI or the largest vocational training program in Sweden (Arbetsmarknadsutbildning), which we will refer to as "Labor Market Training" (LMT).

We explore exceptionally rich population register data which includes annual earnings from 1990 until 2010, providing a follow-up period of 13 years. The empirical strategy is based on difference-in-differences propensity score matching, which explicitly takes into account heterogeneous treatment effects and individual time invariant (fixed) unobserved characteristics. It also enables us to consider the possibility that results are affected by individuals acting on their comparative advantages in practical/ theoretical skills. We achieve this by altering between defining AEI as treatment and LMT as counterfactual state, or vice versa. The intuition is simply that by defining AEI (LMT) as treatment, propensity score matching estimates will mirror the relative program effects for individuals with a relatively high probability to enroll AEI (LMT). The overall findings convey similar implications across a wide set of specifications. Our preferred estimates are based on more than 100 covariates and are robust, e.g., when we check for potential bias by including measures of cognitive and non-cognitive skills (males born 1953 or later) and for "parallel trends" by controlling for dynamic factors (changes) prior to program enrolment. In contrast, the results are sensitive with respect to the length of the follow up period and to the assumed counterfactual state, LMT versus the AEI.

Research comparing general and specific training for the unemployed is scant. Stenberg (2007) is a study similar to the present one, reporting individual fixed effects regression results of average post-program earnings up and until 2003 (six years after enrolment). However, the analyses did not address shape of the trajectories or the longer perspective, instead focusing on cumulative post-program earnings. The estimates indicated throughout that LMT was associated with higher relative earnings, thus corroborating the consensus view regarding outcomes as the LMT individuals' earnings exceeded those of participants in the AEI.

The main contribution of this study is the estimation of the long-term relative earnings impact of general versus specific training of the unemployed 13 years post enrolment. The length of the observation period makes it possible to examine the theoretically ambiguous issue of long-term earnings implications. Specifically, we study if the earlier reported short-term earnings advantage of LMT remains over time, 
whether trends converge or whether the long-term earnings are more in favor of general training. The results provide unique information on whether an expansion of active labor market programs to include general schooling yields scope for efficiency gains. This is of clear policy relevance. A second contribution is that we allow estimates to vary according to individuals' comparative advantages, as our empirical strategy considers heterogeneous program effects and interchangeably models the counterfactual state as LMT or AEI. Our results first confirm earlier findings from studies referred to on vocational or general education for adults. For the case of LMT in Sweden, these results represent a minor contribution given the length of the evaluation. Turning to relative program estimates, the results indicate that specific training outperforms general training in the short run (5-7 years). In the longer perspective, 7-13 years after program enrolment, the estimates tend to converge toward zero. However, we also find evidence revealing substantial heterogeneity. In particular, we find for females with limited education and for residents in a metropolitan labor market region (Stockholm) that an expansion of labor market programs to include general training of the unemployed might enhance efficiency. Finally, we also find indications that vocational training may be a way to compensate for low levels of non-cognitive skills or, conversely, that non-cognitive skills are an important complement to skills obtained in general training.

\section{Earnings returns to specific and general human capital}

The distinction between specific and general skills made by Becker (1964) has often been used to formulate hypotheses on differences in expected short-term and longterm labor market outcomes (e.g. Brunello 2003, Hanushek et al. 2011, Kreuger and Kumar 2004a, 2004b, Shavit and Müller 1998). In the short run, specific skills are assumed to be instantly in demand in the labor market, and to yield short-term average earnings returns which exceed those of general skills. General skills instead enhance the ability to learn, at the expense of a more sluggish transition from training into employment.

In a longer perspective, business cycle fluctuations and technological changes may influence the relative payoff of the different types of human capital. First, by definition, the degree of transferability between employers is lower for specific skills. If the business cycle generates structural changes which force individuals to switch careers, there is a risk attached to investments in specific skills. Relatedly, technological changes could create an advantage for general skills if they enhance the ability to learn new skills. Employers could be more likely to offer further training to these individuals, who then become even less sensitive to changes. In sum, the long-run relative earnings implications are ambiguous, and the time frame emerges as an important aspect to appropriately analyze the impact of general vs. specific skills.

We expect individuals' comparative advantages to affect the choice of investment in specific or general human capital. From this follows two crucial implications. On the one hand, labor market efficiency and societal benefit may be enhanced when program options are increased. On the other hand, it also implies that program types may attract individuals with different characteristics. The latter potentially (but not necessarily) constitutes a source of endogeneity bias in our estimates. This is discussed in detail in Section 5 . 


\section{Institutional setting}

In Sweden, compulsory school is nine years with very limited tracking. For the sample we study, it was followed by two- or three-year programs at the upper secondary school. The two-year programs were mainly vocational, but also included business, social science and technology. The three-year programs were all theoretical and provided eligibility for higher studies.

A notable characteristic of the Swedish educational system is the prevalence of adults in formal education. Since 1969, Swedish municipalities have been obliged by law to offer schooling to adults who wish to re-enroll at the compulsory or upper secondary level. The courses offered are primarily theoretical, with only a limited supply of vocational courses, and are provided by institutes known as Komvux. Participants at Komvux are aged 20 years or older and may be drop-outs from compulsory or upper secondary school. Compared with continental Europe, there is a relatively modest gap in the educational content between the vocational and theoretical programs at the upper secondary level. Many individuals therefore enroll in Komvux to change the direction of their studies. Others enroll to complete a three-year upper secondary diploma and/or to improve grades, potentially to qualify for higher education. Those registered in Komvux are eligible to apply for study allowances that amount to about $€ 1000$ per month (2010 values) of which two-thirds is a loan to be repaid over 25 years.

Vocational courses for adults are mainly offered as active labor market programs. The content of the LMT is typically highly varied, with the five largest sectors represented being technology and science, health care, administration, manufacturing and service (AMS 1999). Importantly, prior to the early 1990s, Komvux enrolment was rarely offered to unemployed individuals. This is partly explained by the fact that UI benefits are more generous than are study allowances (and do not require repayment) and that this would have generated incentives for individuals to register as unemployed before enrolling in Komvux.

Figure 1 shows historical data of the numbers unemployed who were registered in Komvux and LMT. At the start of the 1990s, following an extreme recession which saw unemployment increase from 2 percent to 11 percent, many of the unemployed were assigned to LMT which then grew to its largest size to date. From 1993, as the levels of open unemployment did not decrease in any significant way, the government offered municipalities funding of slots in Komvux, reserved for the unemployed. These funds gradually increased, and the proportion of the unemployed in Komvux was

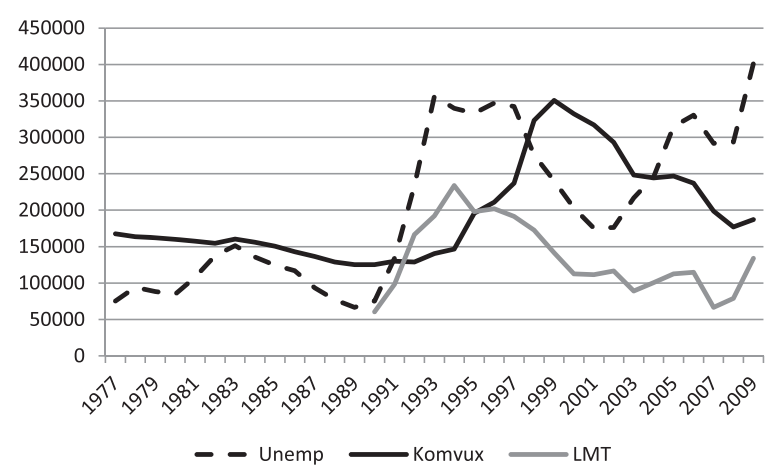

Fig. 1 Number of unemployed and enrollees in Labor Market Training and Komvux 
approximately 10-20 percent in 1993-1996 (Stenberg 2011). The Adult Education Initiative (AEI) was launched in 1997. The government then more than doubled the number of slots in Komvux earmarked for the unemployed and offered one year of full time studies in Komvux with a special grant for education and training (UBS, särskilt utbildningsbidrag), equal to the level of the individual's UI benefits. The AEI instantly became the largest active labor market program, with the participants representing 1.2 percent of the labor force.

The LMT and AEI partly targeted the same groups of the unemployed and prioritized those individuals in a weak position in the labor market. The choice of program was a joint decision between the individual and a case worker at the employment office, with the preferred program usually available if individuals met the formal criteria of being 25-55 years old and eligible for UI benefits. The financial support for the participants in each program was equal to the level of the individuals' UI benefits, and a six-month training period in either program qualified the individual for a new 300-day benefit period. The average program duration in the LMT was 141 days. AEI participants were offered one year of full time studies, but enrollees in 1997 were in 1998 offered a prolonged special grant for education and training (equal to their UI) for the school year 1998-1999, which approximately 35 percent of the individuals accepted. The costs of each type of program were reported as SEK 85,000 (1 SEK $\approx .11 €$ ) per year for the LMT and SEK 34,000 per year for the AEI. This would correspond to similar costs per participant. To simplify the analysis, we will disregard the direct program costs when assessing the relative payoff of the programs. ${ }^{3}$

\section{Data}

This study is based on annual population register data for 1990-2010, which encompasses all individuals residing in Sweden. Our overall sample is restricted to individuals who in 1997 were aged 25-55, received UI benefits and were registered as unemployed for at least one day between the $1^{\text {st }}$ of January and the $30^{\text {th }}$ of June. The unemployment registers provide information on the day of enrolment in the LMT and the end date of this registration. We define the LMT participants as those enrolled in May or later in 1997, to make the timing of the programs reasonably similar. The courses at Komvux are usually ongoing from August until December (autumn semester) and/or from January until the beginning of June (spring semester). To define AEI participants, we set the twofold condition that individuals were registered in Komvux in the autumn semester of 1997 and that they received the special grant for education and training (Särskilt utbildningsbidrag, UBS) that was introduced in 1997 specifically for the AEI. This helps us distinguish between participants in the AEI and participants in the regular Komvux program, who attended the same courses (and in the same classrooms). Individuals who in 1997 were registered in both LMT and AEI are excluded, as are those attending vocational courses within the AEI and those who were registered in any of the two programs in 1996. With these restrictions, the number of observations are 15,129 (LMT), 16,099 (AEI) and 95,939 individuals with "no program". This is the sample used in the analyses unless stated otherwise.

Figure 2 displays the trajectories of annual earnings 1990-2010. The average earnings for 1990-1996 of the two groups of program participants are remarkably similar. At face value, the post-program earnings of males indicate an advantage of the LMT, but 


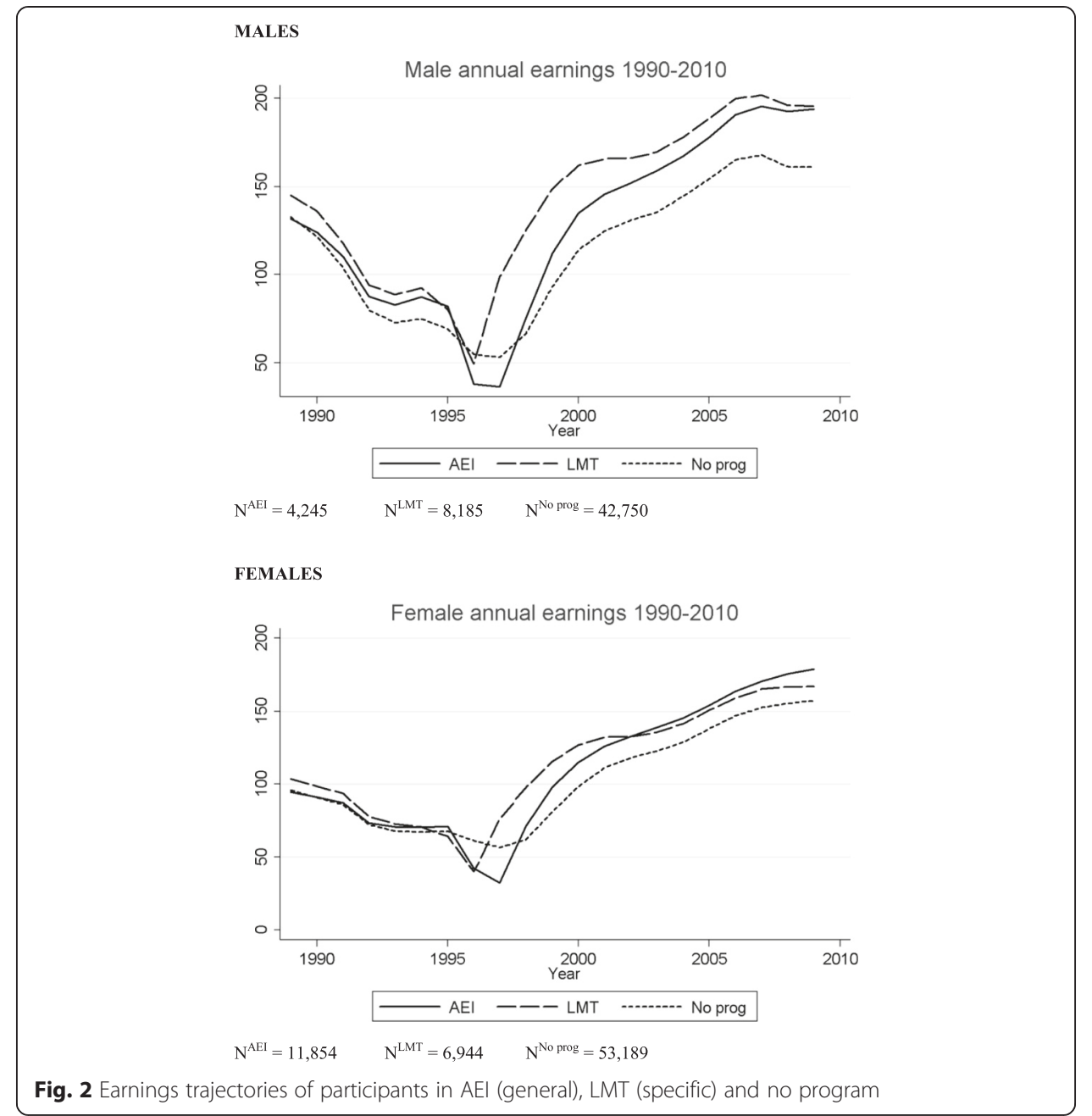

the general training appears to be more beneficial for females. To the best of our knowledge, this kind of descriptive evidence has not been presented earlier. Those not assigned to a program are characterized by lower earnings levels in the latter part of the observation window.

Table 1 presents means of selected variables. Many of the characteristics are significantly different between the participants in AEI and LMT ( $p$-values $<.05$, see Additional file 1: Table S1), while the averages of those not enrolled in a program tend to be more alike LMT. Comparing program participants, those in AEI are on average about 2.5 years younger, have completed fewer years of schooling and are more often employed in the public sector. ${ }^{4}$ Among females, the AEI enrollees were more often on maternal leave and had more children at home than the LMT participants. Concerning unemployment history, the differences between the groups are relatively modest, although statistically significant. Table 2 describes the schooling completed until 2004 by participants in the AEI. For males born in 1953 or later, we also have information on test scores of cognitive and non-cognitive skills from the mandatory military enlistment, completed at age 18-19 (scaling 1-9, where 9 is the best). The conventional view is that general training attracts individuals with higher ability, but the difference in 
Table 1 Sample means by program status 1997

\begin{tabular}{|c|c|c|c|c|c|c|}
\hline & \multicolumn{3}{|l|}{ Males } & \multicolumn{3}{|l|}{ Females } \\
\hline & AEl & LMT & No prog & AEI & LMT & No prog \\
\hline Age & 35.053 & 37.397 & 37.473 & 35.083 & 37.882 & 36.599 \\
\hline Children & 0.841 & 0.921 & 0.857 & 1.500 & 1.240 & 1.391 \\
\hline No children & 0.551 & 0.506 & 0.540 & 0.246 & 0.337 & 0.284 \\
\hline One child & 0.191 & 0.202 & 0.202 & 0.239 & 0.254 & 0.253 \\
\hline Two children & 0.167 & 0.194 & 0.162 & 0.337 & 0.278 & 0.303 \\
\hline Child 0-3 & 0.153 & 0.160 & 0.148 & 0.265 & 0.181 & 0.261 \\
\hline Child 4-6 & 0.127 & 0.138 & 0.122 & 0.300 & 0.219 & 0.241 \\
\hline Married & 0.265 & 0.319 & 0.293 & 0.410 & 0.410 & 0.403 \\
\hline Divorced & 0.096 & 0.119 & 0.127 & 0.129 & 0.170 & 0.150 \\
\hline Yrs of sch & 10.840 & 11.325 & 11.170 & 10.821 & 11.657 & 11.122 \\
\hline No upp sec sch & 0.843 & 0.715 & 0.736 & 0.861 & 0.624 & 0.759 \\
\hline 2-yr upp sec & 0.605 & 0.493 & 0.481 & 0.634 & 0.422 & 0.514 \\
\hline Vocational 2 years & 0.163 & 0.118 & 0.129 & 0.406 & 0.260 & 0.328 \\
\hline Business 2 years & 0.072 & 0.030 & 0.037 & 0.170 & 0.140 & 0.143 \\
\hline Social sci 2 years & 0.045 & 0.022 & 0.025 & 0.055 & 0.036 & 0.043 \\
\hline Technology 2 years & 0.310 & 0.327 & 0.292 & 0.023 & 0.023 & 0.023 \\
\hline Business 3 years & 0.037 & 0.072 & 0.065 & 0.035 & 0.114 & 0.070 \\
\hline Tertiary & 0.060 & 0.162 & 0.147 & 0.053 & 0.215 & 0.128 \\
\hline Regional employment & 0.725 & 0.722 & 0.722 & 0.692 & 0.695 & 0.693 \\
\hline Stockholm & 0.145 & 0.123 & 0.128 & 0.107 & 0.159 & 0.125 \\
\hline Inland of Norrland & 0.079 & 0.078 & 0.087 & 0.068 & 0.066 & 0.067 \\
\hline Farming/Mining & 0.012 & 0.019 & 0.026 & 0.007 & 0.007 & 0.009 \\
\hline Construction & 0.060 & 0.122 & 0.084 & 0.006 & 0.008 & 0.007 \\
\hline Manufacturing & 0.089 & 0.140 & 0.102 & 0.043 & 0.072 & 0.054 \\
\hline Finance/insurance & 0.076 & 0.089 & 0.070 & 0.054 & 0.093 & 0.066 \\
\hline Public sector & 0.135 & 0.086 & 0.104 & 0.394 & 0.254 & 0.350 \\
\hline Other sector & 0.205 & 0.191 & 0.204 & 0.173 & 0.215 & 0.203 \\
\hline Foreign born & 0.168 & 0.190 & 0.222 & 0.136 & 0.193 & 0.163 \\
\hline Parent $>01990$ & 0.092 & 0.090 & 0.089 & 0.262 & 0.207 & 0.221 \\
\hline Parent > 01995 & 0.059 & 0.062 & 0.048 & 0.296 & 0.207 & 0.239 \\
\hline Sick > 01990 & 0.745 & 0.729 & 0.728 & 0.785 & 0.739 & 0.758 \\
\hline Sick >0 1995 & 0.197 & 0.178 & 0.187 & 0.280 & 0.264 & 0.265 \\
\hline Social welf. >0 1990 & 0.150 & 0.140 & 0.179 & 0.142 & 0.128 & 0.150 \\
\hline Social welf. > 01995 & 0.157 & 0.156 & 0.194 & 0.142 & 0.150 & 0.155 \\
\hline UI >0 1990 & 0.168 & 0.157 & 0.194 & 0.196 & 0.174 & 0.202 \\
\hline UI>0 1995 & 0.688 & 0.706 & 0.758 & 0.695 & 0.680 & 0.729 \\
\hline Days unempl 1995 & 230.147 & 232.317 & 251.439 & 214.498 & 219.813 & 228.692 \\
\hline Max unempl 1995 & 0.159 & 0.145 & 0.180 & 0.163 & 0.150 & 0.182 \\
\hline No unempl 1995 & 0.187 & 0.163 & 0.122 & 0.193 & 0.175 & 0.156 \\
\hline No earn 1995 & 0.246 & 0.233 & 0.291 & 0.203 & 0.232 & 0.223 \\
\hline Observations & 4246 & 8185 & 42,750 & 11,857 & 6944 & 53,189 \\
\hline
\end{tabular}


Table 2 Content of general training within the AEl. Credits expressed in years of full-time studies

\begin{tabular}{|c|c|c|}
\hline & Males & Females \\
\hline $\bar{N}$ & 4245 & 11,854 \\
\hline Total registered course credits at Komvux (years) & 1.694 & 1.969 \\
\hline Total completed course credits at Komvux (years) & .883 & 1.112 \\
\hline Fraction completing zero credits & .150 & .103 \\
\hline Fraction completing credits $>0$ but $<.25$ years of $A E$ & .082 & .062 \\
\hline Fraction completing credits $>.25$ but $<.5$ years of $\mathrm{AE}$ & .115 & .085 \\
\hline Fraction completing credits $>.5$ but $<1$ year of $\mathrm{AE}$ & .278 & .267 \\
\hline Fraction completing more than 1 year of AE credits & .376 & .483 \\
\hline Proportion registered in compulsory level courses & .291 & .278 \\
\hline Registered compulsory credits, average & .263 & .217 \\
\hline Completed compulsory credits, average & .077 & .073 \\
\hline Completed compulsory credits, if registered at level & .263 & .263 \\
\hline Proportion registered in upper secondary level courses & .919 & .951 \\
\hline Registered upper secondary credits, average & 1.418 & 1.730 \\
\hline Completed upper secondary credits, average & .799 & 1.028 \\
\hline Completed upper secondary credits, if registered at level & .870 & 1.081 \\
\hline \multicolumn{3}{|l|}{ Proportions in type of upper secondary course registration } \\
\hline - English & .749 & .718 \\
\hline - Swedish & .739 & .729 \\
\hline - Mathematics & .757 & .711 \\
\hline - Social sciences & .810 & .879 \\
\hline - Natural sciences & .368 & .377 \\
\hline - Human sciences (e.g., foreign languages) & .160 & .217 \\
\hline - Computer sciences & .719 & .761 \\
\hline - Health-related subjects (e.g., nursing) & .220 & .446 \\
\hline - Vocational courses & .000 & .000 \\
\hline Proportion completing some tertiary level education & .139 & .171 \\
\hline Completed tertiary education, average & .311 & .383 \\
\hline Completed tertiary education, if registered at level & 2.235 & 2.244 \\
\hline Total adult education completed (years) & 1.186 & 1.484 \\
\hline
\end{tabular}

cognitive test scores is small (4.34 vs. 4.31$)$ and not statistically significant ( $p$-value .530). The average score for non-cognitive skills is marginally higher for the LMT sample (4.23 vs. $4.31, p$-value .034). ${ }^{5}$

\section{Empirical strategy}

In this section we describe our empirical strategy, difference-in-differences propensity score matching (DID-PSM) (e.g. Smith and Todd 2005). Matching estimators generally take into account that treatment effects are heterogeneous by explicitly seeking to compare comparable individuals. Below, we first describe the case of a conventional average treatment effect on the treated (ATT) of a particular program. We then define the relative ATT, which directly compares participants in the AEI and LMT. The interpretation of the relative ATT estimates is discussed in Section 5.3. 


\subsection{Difference-in-differences propensity score matching}

In our empirical implementation, year $t$ is $1997, t$ - denotes a year prior to program and $t+$ is $(1998,1999, \ldots, 2010)$. If a program occurs at time $t$, the change in annual earnings $\left(Y_{t+}-Y_{t-}\right)=\Delta Y$ is calculated for each individual. In a potential outcomes framework, we wish to compare $\left(\Delta Y_{1}-\Delta Y_{0}\right)$, where subscripts denote 1 if treated and 0 if untreated (for now). One of these is always missing. We therefore make the assumption that conditional on individuals' pre-program observable characteristics $\mathrm{X}$, and denoting $\mathrm{D}=1$ for actual treatment and zero otherwise:

$$
\left(\Delta \mathrm{Y}_{1}-\Delta \mathrm{Y}_{0}\right) \perp \mathrm{D} \mid \mathrm{X} \text {. }
$$

If this assumption holds, it also holds for some function of $\mathrm{X}$, such that the matching is reduced to conditioning on a scalar (Rosenbaum and Rubin, 1983):

$$
\left(\Delta \mathrm{Y}_{1}-\Delta \mathrm{Y}_{0}\right) \perp \mathrm{D} \mid \mathrm{P}(\mathrm{X})
$$

The function $\mathrm{P}(\mathrm{X})$ is the propensity score, in our case a probit estimate of the probability of enrolment in a program. Each treated is matched with an untreated who is the nearest neighbor in terms of the probit estimate. Because $\Delta Y_{O}$ cannot be observed for treated individuals $(D=1)$, it is estimated by the observed outcomes of the matched comparisons. The ATT is the average difference in $\Delta Y$ between samples of treated and untreated which have been balanced on the covariates. Formally:

$$
\Delta \mathrm{Y}_{\mathrm{ATT}}=\left(\Delta \mathrm{Y}_{1} \mid \mathrm{D}=1, \mathrm{P}(\mathrm{X})\right)-\left(\Delta \mathrm{Y}_{0} \mid \mathrm{D}=0, \mathrm{P}(\mathrm{X})\right)
$$

To give estimates of the ATT a causal interpretation, one needs to assume: $i$ ) that $\mathrm{P}(\mathrm{X})<1$; ii) that program participation does not affect the earnings of other individuals and; iii) conditional on the covariates in $\mathrm{X}$, that the mechanisms behind enrolment decisions are independent of potential future earnings changes under non-treatment. The crucial assumption is iii because it is not possible to rule out that there are remaining unobserved factor(s) which may correlate with both participation and future earnings. ${ }^{6}$ The DID-PSM estimator adjusts for time invariant unobserved heterogeneity affecting earnings. Our balancing tests encompass a rich set of covariates that include age, regional employment levels, dummies for region of residence (23 categories), employment sector (seven categories), prior education level (six categories) and educational track (six categories), number of children at home (six categories), age of children (6 categories), indicators of marital status or divorce, pre-treatment annual earnings trajectories for 1990-1995 (1996 with our extended model, see below), and four different types of social insurance benefits in 1990-1995 (1996) related to unemployment insurance, parental leave, sick-leave and social welfare, applying both dummy variables (zero earnings, incidence of the various benefits) and continuous measures of amounts. We further balance on days registered as unemployed each year in 1992-1995 (1996) and on indicator variables if either zero days or the maximum number of days (365/366). In total, our balancing tests encompass at least 132 variables.

Our main concerns regarding sources of potential bias are differences in unobserved ability and in time-varying unobserved factors (see Biewen et al. 2014 for an extensive discussion on specification issues). As a check for ability bias in our estimates, for males born 1953 or later, we compare the results when including and excluding test scores relating to cognitive and non-cognitive skills. These checks indicate that abilty 
bias is not a major concern, as the change in estimation results corresponds to less than .5 percentage points of annual earnings (this is the case also for our relative ATT).

Regarding time-varying unobserved factors, changes in motivation or health may not be captured by our covariates. ${ }^{7}$ A common critique of difference-in-difference estimators is that a temporary earnings drop in the year prior to program enrolment among the treated generates an upward bias because the earnings level does not reflect the individual's true productivity (Ashenfelter 1978). The baseline model we use in the results section, unless otherwise stated, does not consider covariates recorded in 1996, with pre-program earnings defined as the average of the annual earnings in 1993-1995. A contrasting approach is to assume that changes occurring shortly prior to program imply changes with permanent effects which must be controlled for (e.g., Heckman and Smith 1999, Heckman et al. 1999). We applied extended versions of our estimation models to consider changes in transfers and earnings $1995-1996 .{ }^{8}$ If our estimates are affected by diverging parallel trends, or time-varying unobserved characteristics, one would expect results to systematically change by model specifications. ${ }^{9}$ However, the different specifications generally yield negligible differences in (relative) ATT estimates. In Sections 6, 7 and 8, the extended model results are reported when relevant. Overall, the stability of our findings with respect to the extended model specification and the check for potential ability bias indicate support for our empirical strategy. ${ }^{10}$

\subsection{Relative program effects}

The estimated ATT for AEI and LMT differ in two dimensions; the type of treatment and the group of participants. If program effects are heterogeneous across individuals, then the ATTs for different participant groups are not directly comparable (i.e. ATT may be different from the average treatment effect, ATE). To directly compare AEI and LMT, one may estimate a relative ATT by applying the same reasoning as in the case of the ATT discussed above, but consider $\mathrm{D}=1$ the treatment and $\mathrm{D}=0$ the alternative treatment (instead of "no treatment"). We thereby obtain an estimate of relative program effects for comparable program participants. To give a hypothetical example, if the program effects are correlated with say, age, separate estimates of ATT for the AEI and the LMT may differ only because of participants' different age structure. The relative ATT would correct this potential flaw by comparing $\Delta \mathrm{Y}$ of program participants of the same age, where the age variable has been balanced between the two groups.

In Table 3, the probit model estimates of $\mathrm{P}(\mathrm{X})$ are presented where the probability of treatment is AEI enrollment and LMT is the alternative state. ${ }^{11}$ In the Additional file 1, balancing tests pertaining to matched samples are given in Tables S2 and S3. Equality of means between the treated and matched comparisons are not rejected. This holds for all of the estimates discussed in the empirical section. ${ }^{12}$

\subsection{Comparative advantages}

A basic motivation for policy makers to expand the program types available is that it allows individuals to act on their personal abilities. Figure 3 shows the distribution of estimated probabilities of AEI enrolment based on estimates of $\operatorname{Pr}[\mathrm{AEI}]$ or $\operatorname{Pr}[\mathrm{LMT}]$ in the probit step. In the segment indicating a high probability of AEI enrolment, one might assume an overrepresentation of individuals with a comparative advantage in 
Table 3 Probit model estimates (marginal) of the relative probability of enrolment in AEI

\begin{tabular}{|c|c|c|}
\hline & Males ${ }^{a)}$ & Females $^{\mathrm{a})}$ \\
\hline Age & $-0.0120^{*}$ & \\
\hline Less than 9 years & $0.3945^{* * *}$ & \\
\hline 9 years of sch & $0.4602^{* * *}$ & \\
\hline 2-yr upp sec & $0.4289^{* * *}$ & $0.2103^{* * *}$ \\
\hline Social sci 2 years(d) & $0.0943^{* *}$ & $0.0832^{* * *}$ \\
\hline Vocation 2 years $(d)$ & $0.0848^{* * *}$ & $0.1056^{* * *}$ \\
\hline Technology 2 years(d) & $-0.0450^{* *}$ & 0.0360 \\
\hline Business 3 years $(d)$ & $0.1142^{* * *}$ & $0.0696^{* * *}$ \\
\hline 12 years of sch & $0.3564^{* * *}$ & $0.0686^{* * *}$ \\
\hline Business 3 years & $-0.0535^{*}$ & $-0.0618^{* *}$ \\
\hline 15 years of sch & $0.2542^{* * *}$ & \\
\hline Regional employm & $0.9272^{* * *}$ & \\
\hline Stockholm(d) & 0.0250 & \\
\hline Farmin/mining(d) & $-0.1497^{* * *}$ & -0.0571 \\
\hline Construction(d) & $-0.1811^{* * *}$ & -0.0627 \\
\hline Manufacturing(d) & $-0.1530^{* * *}$ & $-0.1330^{* * *}$ \\
\hline Finance/insur(d) & $-0.0780^{* * *}$ & $-0.0808^{* * *}$ \\
\hline Public sector(d) & $0.0669^{* * *}$ & $0.0911^{* * *}$ \\
\hline Other sector(d) & $-0.0566^{* * *}$ & $-0.0498^{* * *}$ \\
\hline Foreign born(d) & -0.0202 & \\
\hline Divorced(d) & -0.0236 & $-0.0281^{*}$ \\
\hline One child(d) & $-0.0248^{*}$ & $0.0417^{* * *}$ \\
\hline Two children(d) & $-0.0484^{* * *}$ & $0.0764^{* * *}$ \\
\hline Three children(d) & $-0.0391^{*}$ & $0.0975^{* * *}$ \\
\hline Four children(d) & -0.0482 & $0.0901^{* * *}$ \\
\hline Child 0-3(d) & $0.0365^{*}$ & \\
\hline Child 7-10(d) & 0.0116 & \\
\hline Child 11-15(d) & $0.0420^{*}$ & \\
\hline Child $>17(d)$ & $-0.0439 * *$ & \\
\hline Parental 1993 & $-0.0537^{*}$ & \\
\hline Parental 1995 & $-0.0635^{* *}$ & \\
\hline Parent $>0$ 1990(d) & 0.0374 & \\
\hline Parent > $01991(\mathrm{~d})$ & 0.0154 & -0.0199 \\
\hline Parent $>0$ 1993(d) & 0.0201 & \\
\hline Parent > 0 1994(d) & $0.0344^{* *}$ & \\
\hline Parent > 0 1995(d) & $0.0304^{*}$ & \\
\hline Earnings 1990 & -0.0110 & \\
\hline Earnings 1991 & $-0.0226^{*}$ & \\
\hline Earnings 1992 & 0.0112 & \\
\hline Earnings 1993 & -0.0098 & \\
\hline Earnings 1994 & $-0.0238^{* *}$ & 0.0127 \\
\hline Earnings 1995 & $0.0830^{* * *}$ & \\
\hline Zero earn $1991(\mathrm{~d})$ & -0.0138 & \\
\hline Zero earn 1993(d) & -0.0206 & -0.0177 \\
\hline
\end{tabular}


Table 3 Probit model estimates (marginal) of the relative probability of enrolment in AEI (Continued)

\begin{tabular}{|c|c|c|}
\hline Zero earn 1994(d) & -0.0149 & \\
\hline Unemp ben 1990 & $0.0776^{*}$ & \\
\hline Unemp ben 1991 & -0.0272 & $-0.0615^{*}$ \\
\hline Unemp ben 1993 & $-0.0465^{*}$ & $-0.0335^{*}$ \\
\hline Unemp ben > $01991(d)$ & 0.0200 & \\
\hline Unemp ben > 0 94(d) & $-0.0320^{*}$ & \\
\hline Unemp ben > 0 1995(d) & $0.0268^{*}$ & \\
\hline Days unemp 1992 & 0.0001 & \\
\hline Days unemp 1993 & 0.0001 & \\
\hline Days unemp 1994 & $0.0001^{* * *}$ & \\
\hline Days unemp 1995 & -0.0000 & \\
\hline Max unemp 1992(d) & $0.0361^{*}$ & \\
\hline Max unemp 1993(d) & 0.0234 & \\
\hline Max unemp 1994(d) & 0.0207 & \\
\hline Max unemp 1995(d) & $0.0298^{*}$ & \\
\hline No unemp 1992(d) & 0.0155 & \\
\hline No unemp 1993(d) & 0.0347 & \\
\hline No unemp 1995(d) & $0.0489^{*}$ & \\
\hline Sick leave 1990 & -0.0398 & \\
\hline Sick leave 1992 & $-0.0596^{* *}$ & \\
\hline Sick leave 1994 & -0.0278 & $-0.0541^{* *}$ \\
\hline Sick leave 1995 & -0.0412 & \\
\hline Sick > 0 1990(d) & 0.0215 & \\
\hline Sick > 0 1991(d) & $0.0229^{*}$ & 0.0140 \\
\hline Sick > 0 1993(d) & 0.0181 & $0.0180^{*}$ \\
\hline Sick > 0 1995(d) & $0.0302^{*}$ & \\
\hline Social welf 1992 & $0.1882^{*}$ & \\
\hline Social welf 1993 & $-0.1818^{*}$ & -0.1113 \\
\hline Social welf 1994 & $-0.1915^{*}$ & \\
\hline Social welf 1995 & -0.1686 & \\
\hline Social welf > 0 1990(d) & 0.0221 & \\
\hline Social welf > 0 1995(d) & -0.0103 & \\
\hline Observations & 12,098 & 17,509 \\
\hline Pseudo R-squared & 0.0863 & 0.1066 \\
\hline \multicolumn{3}{|c|}{$\begin{array}{l}\text { (d) }=\text { dummy variable } \\
\text { a) Earnings and transfers expressed in SEK 100,000 (2010 values). For reasons of space, coefficients not displayed include } \\
\text { age-dummies (males) and } 13 \text { additional regional dummies. Estimates are also based on interaction variables which for } \\
\text { males only include (Social welf. }>01990^{*} U 1 \text { 1 1995). For females, the indicator variable of } 9 \text { years of schooling is interacted } \\
\text { with "no unemployment } 1995 \text {; five interaction variables involve "no upper secondary school" (age at immigration, sick } \\
\text { leave 1992, social welfare } 1990 \text { and } 1995 \text { and earnings 1995); two interaction variables involve two year upper secondary } \\
\text { school (no unemployment } 1995 \text {, and age at immigration); Stockholm is interacted with sick leave benefits 1991; and fi- } \\
\text { nally earnings } 1995 \text { squared is also included } \\
{ }^{*} p<0.05,{ }^{* *} p<0.01,{ }^{* * * *} p<0.001\end{array}$} \\
\hline
\end{tabular}

theoretical rather than vocational skills. If the matched propensity scores are symmetrical between the alternative set-ups, these will have no bearing on our estimates. However, the distributions in Fig. 3 are clearly tilted toward the probability of the program 


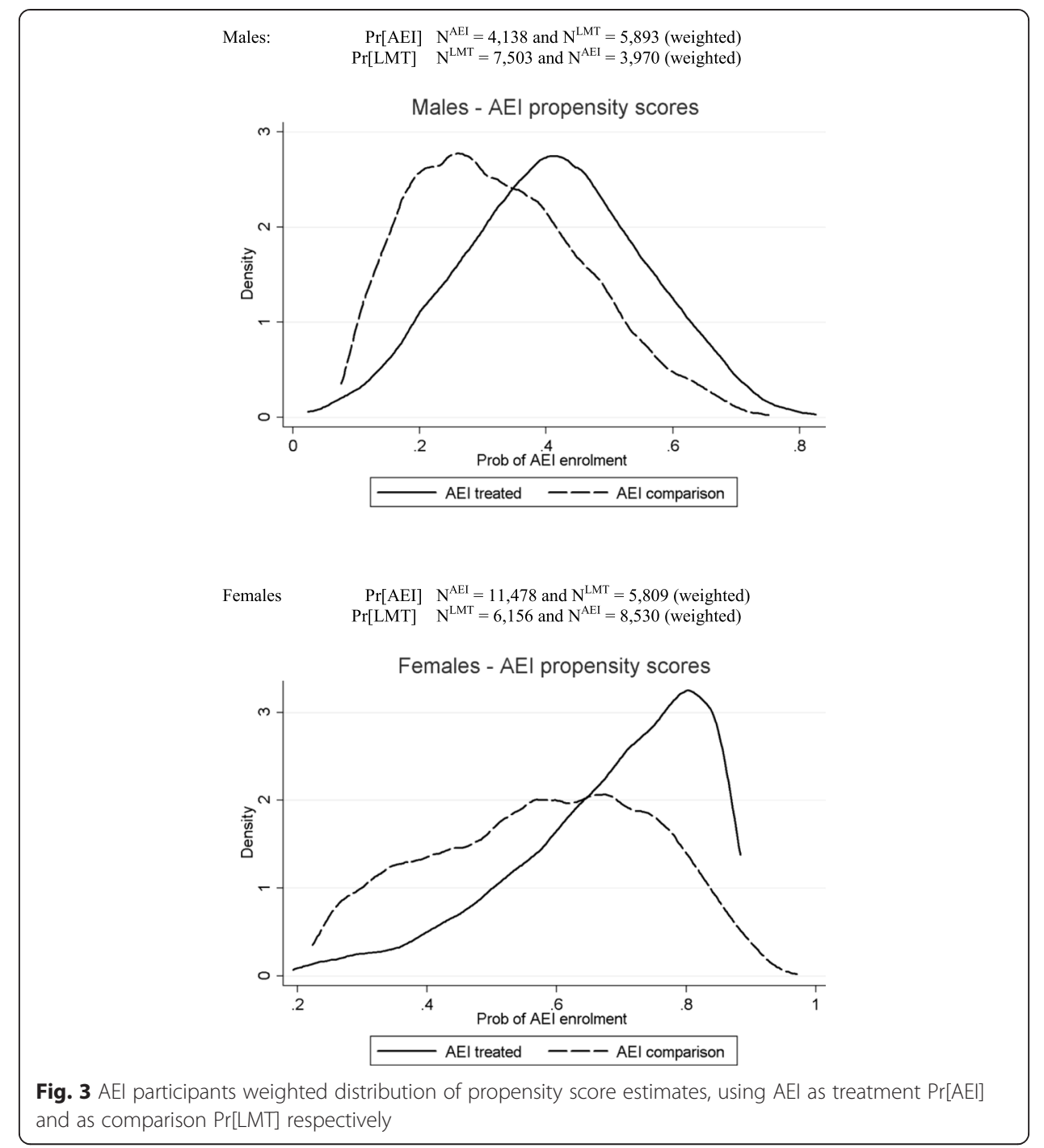

defined as "treatment", and away from the program defined as alternative treatment ("comparison"). In fact, we do not obtain balanced samples if we use the same Probit specification for of $\operatorname{Pr}[\mathrm{LMT}]$ and $\operatorname{Pr}[\mathrm{AEI}] .{ }^{13}$ This makes it potentially important for our estimates if we consider matching based on estimates of $\operatorname{Pr}[\mathrm{AEI}]$ or $\operatorname{Pr}[\mathrm{LMT}]$.

The $\operatorname{Pr}[\mathrm{AEI}]$ vs $\operatorname{Pr}[\mathrm{LMT}]$ approaches are asking two different questions. Assuming that all individuals in our sample have decided to enroll in a program, and that they choose freely between only two existing programs, the $\operatorname{Pr}[\mathrm{AEI}]$ case evaluates the relative ATT for the AEI participants had they enrolled LMT. With Pr[LMT], one instead evaluates the relative ATT for LMT participants had they enrolled AEI. Thus, if individuals act on their comparative advantages, one could expect the relative estimate to indicate a more beneficial effect of the program considered as "treatment" $(D=1)$. However, hypothetically, an ability (e.g. reading skills or practical handiness) which generates a comparative advantage may also affect earnings independently of a program, to yield bias in our relative estimates. Therefore, results are presented below for both $\operatorname{Pr}[\mathrm{AEI}]$ and $\operatorname{Pr}[\mathrm{LMT}]$. 


\section{Results}

\subsection{Evaluating programs separately}

We first give an account of the ATT of each program compared with "no program". Figure 4 displays the full model DID-PSM estimates separately for the AEI and the LMT, in each case based on samples balanced on 132 variables. ${ }^{14}$ The findings indicate that estimates are positive and statistically significant in the years following program participation, with LMT associated with an initially relatively large earnings payoff. There are several earlier studies which have evaluated these respective types of programs separately (for LMT, see references in footnote 1, for Komvux see Stenberg and Westerlund 2008, Stenberg 2011, Stenberg et al. 2014). These estimates represent a minor contribution in the sense that the follow up period of LMT is here longer than in earlier studies, for the most part confirming earlier reported significantly positive estimates. The long term results are also in line with Lechner et al. (2011) for German training programs.

For completeness, Additional file 1: Tables S4 and S5 provide estimates from simple OLS regressions assessing each program compared with "no program" (1) without

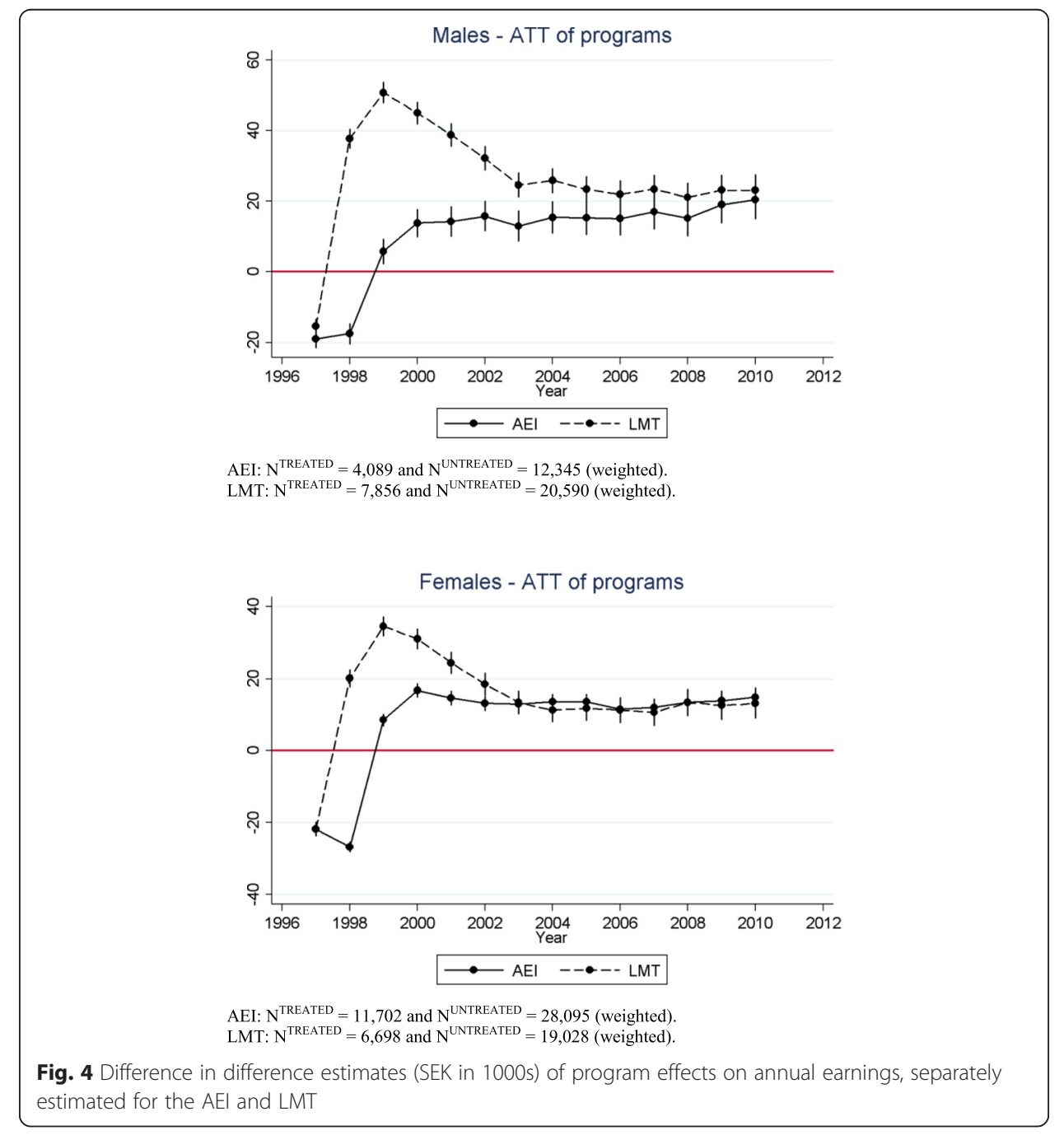


control variables and (2) with individual and year fixed effects. The fixed effects models yield, at the end of the observation window, higher parameters of the AEI. However, the impression from Fig. 4 is that specific training is associated with higher short-run estimates and that the long-run estimates of general training only in a few cases (females) catch up with those of specific training. As discussed in Section 5.2, the separate program estimates of the ATT are not necessarily comparable. We therefore turn to the evaluation of relative ATT as our main question of interests is whether changing the program content for individuals from LMT to the AEI, or vice versa, could enhance the discounted value of earnings streams.

\subsection{Relative program effects}

Figure 5a (males) and 5b (females) show difference-in-difference PSM estimates of the relative ATT between participants of the AEI and the LMT. As expected, the results indicate an initial drop in the relative earnings of the AEI participants before estimates tend to converge or switch signs (females). ${ }^{15}$ The initial relative earnings drop of the AEI may be due to locking in effects, as duration of AEI program is most often longer than LMT, or that human capital investment in LMT is more closely related to the jobmarket to increase short run employment opportunities. To check the impact of the first hypothesis, we examine if estimates differ when we condition AEI program lengths to be one, two, three or four semesters. Figure 6 demonstrates that the initial drop is modest for those with one semester in the AEI, and then increases with the number of

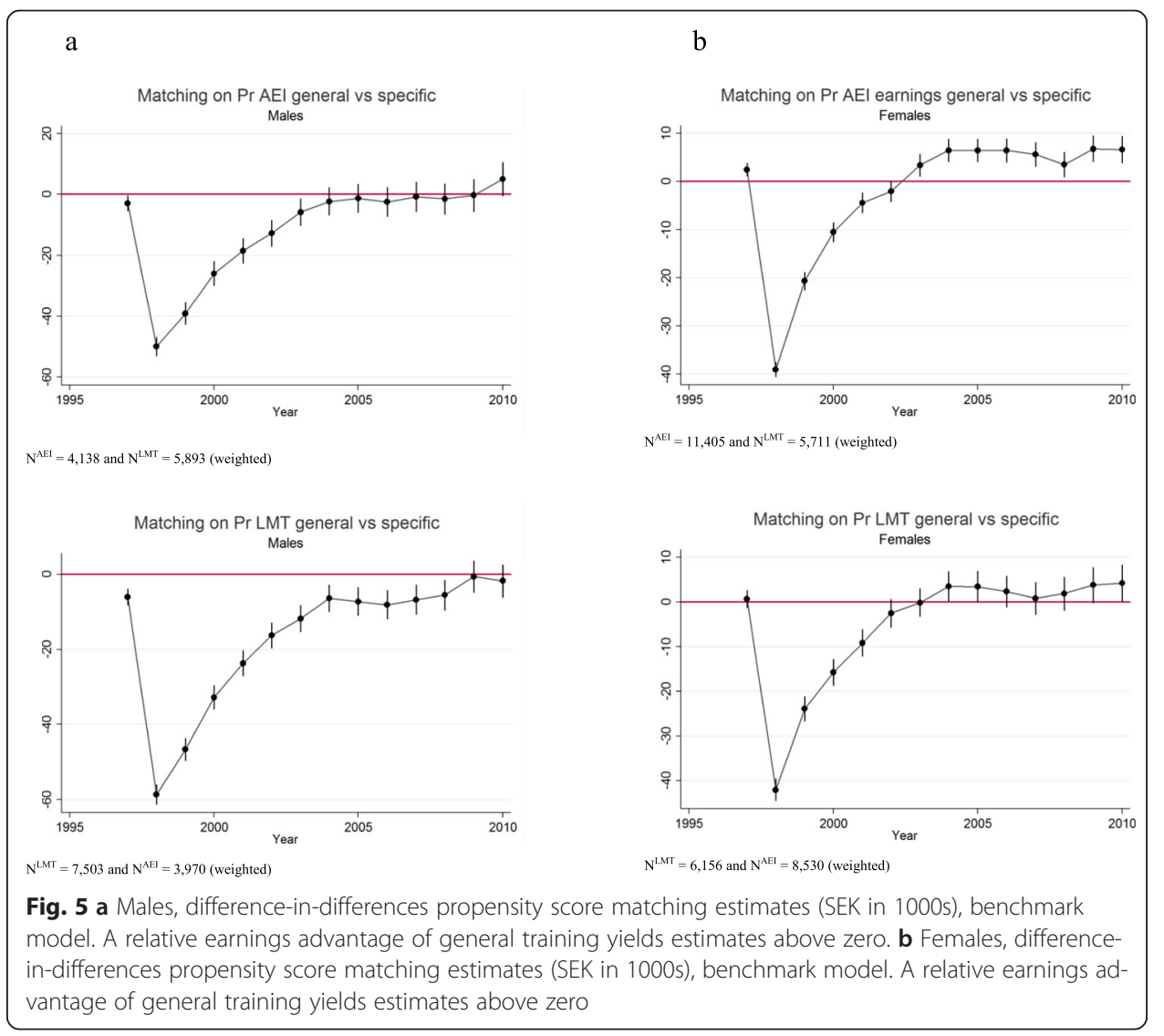




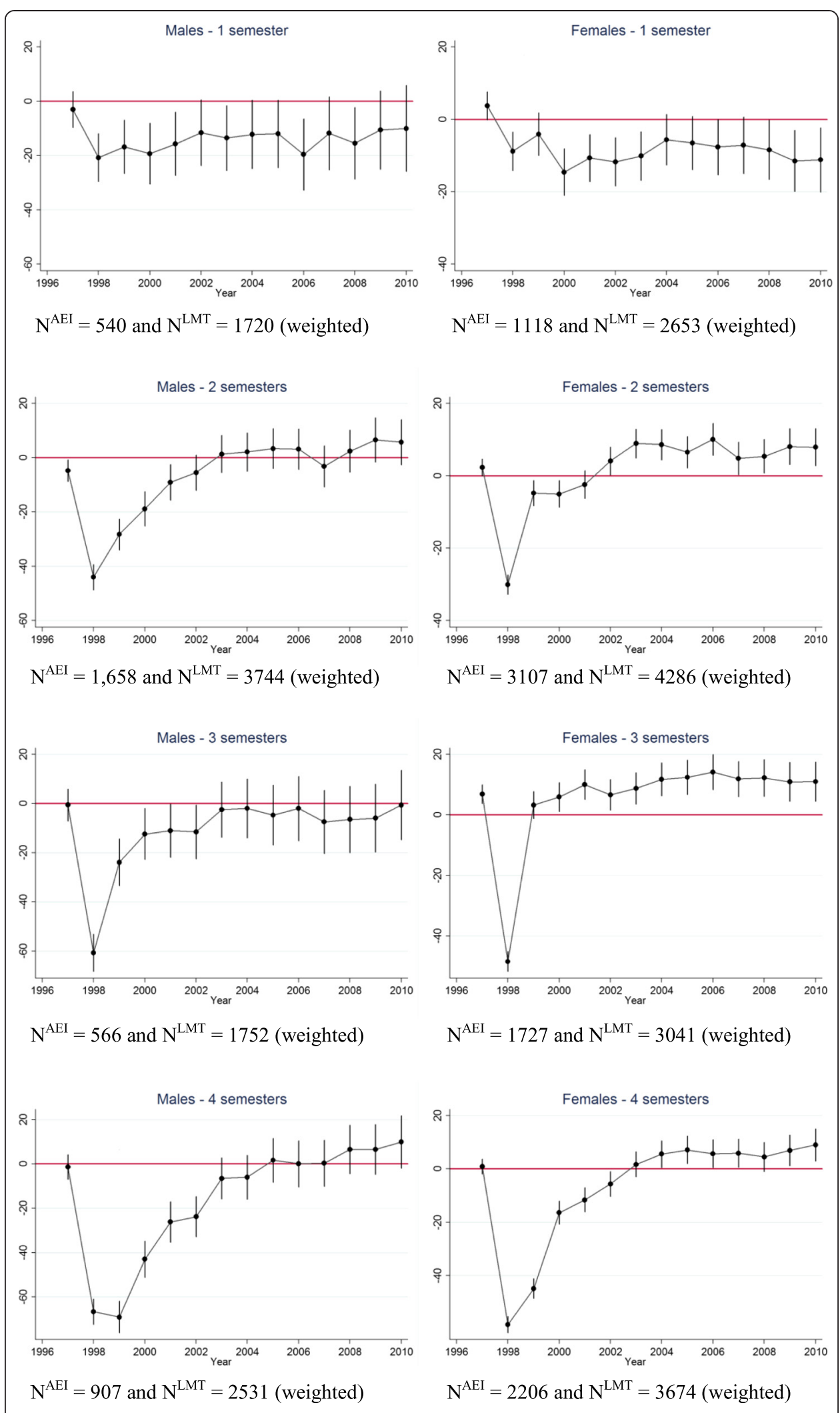

Fig. 6 Relative program general vs. specific difference-in-differences (SEK in 1000s) propensity score matching estimates, matching on $\operatorname{Pr}[\mathrm{AEI}]$ 
semesters registered, in particular evident for males. This suggests that a locking in effect explains a non-trivial part of the initial drop. In the longer run, the relative estimates of the AEI increase when we condition the duration of AEI to two semesters, rather than one, but estimates only increase modestly as we restrict AEI participants to three or four semesters of studies. The pattern is at least partly consistent with the decreasing returns to program length reported for Job Corps in the US and for labor market training programs in Germany (Flores et al. 2012, Kluve et al. 2012).

When we switch between matching on $\operatorname{Pr}[\mathrm{LMT}]$ and $\operatorname{Pr}[\mathrm{AEI}]$, the estimates change in the expected direction (as described in Section 5.3), favoring the program chosen as the "treatment" indicator. This is consistent with that individuals act on their comparative advantages. The relative treatment effects estimated from $\operatorname{Pr}[\mathrm{AEI}]$ tend to converge for males, while the estimates for females are significantly above zero from 2003 and onward. These findings are shifted downward when the matching is based on estimates of $\operatorname{Pr}[\mathrm{LMT}]$, positive but closer to zero for females and often significantly below zero for males. Robustness checks for parallel trends via the extended model corroborate the results.

To gauge the long term implications of the estimates, we extrapolate the last estimate (from 2010) into future years. We assume a two percent discount rate (base year is 1997) and that everyone retires at age 65, accounting for the age structure of the samples (the cohorts retire gradually between 2007 and 2037). This framework is used repeatedly below to assess what the estimates imply for the net benefits. ${ }^{16}$

For males, even if we extrapolate the largest estimate into future years, the present value of the estimated relative payoff of AEI vs LMT would still not cover the initial relative earnings loss during 1998-2004 (recall that the direct costs are approximated as equal for the two programs). For the sample of females, extrapolation of the estimates based on $\operatorname{Pr}[\mathrm{AEI}]$ implies that the initial relative earnings losses (costs) in 1998-2002 are recovered by approximately $2020 .{ }^{17}$ The youngest cohort in the sample is then 48 years old, and about half of the individuals are still below age 65 . However, the estimates based on $\operatorname{Pr}[\mathrm{LMT}]$ do not support a conclusion that the initial earnings drop for enrollees in AEI is recovered before the last cohort retires. Thus, the results so far provide no robust evidence for the hypothesis that general training programs would be relatively more beneficial in the long term.

\section{Heterogeneous effects}

We now turn to analyses of subgroups. ${ }^{18}$ Figure 7 present results for samples residing in the commuting areas (as defined by Statistics Sweden) of Stockholm, as well as Gothenburg and Malmö, the second and third largest cities in Sweden. The Stockholm local labor market is by far the biggest in Sweden, with more than one million employed (almost 25 percent of national employment). It is characterized by low unemployment and a high level of diversity. The results for the Stockholm samples contrast with the full sample results. For males, AEI is linked with relative earnings which exceed the LMT matched comparisons. The recorded earnings difference is large also when based on $\operatorname{Pr}[\mathrm{LMT}]$, and statistically significant from 2007. In extrapolation, the estimated differences above SEK 20,000 imply a recovery of the initial earnings disadvantage by 2015 and 2018, respectively. For females, all estimates are positive from 2004 but with a slight tendency to converge back toward zero. Nevertheless, the results 


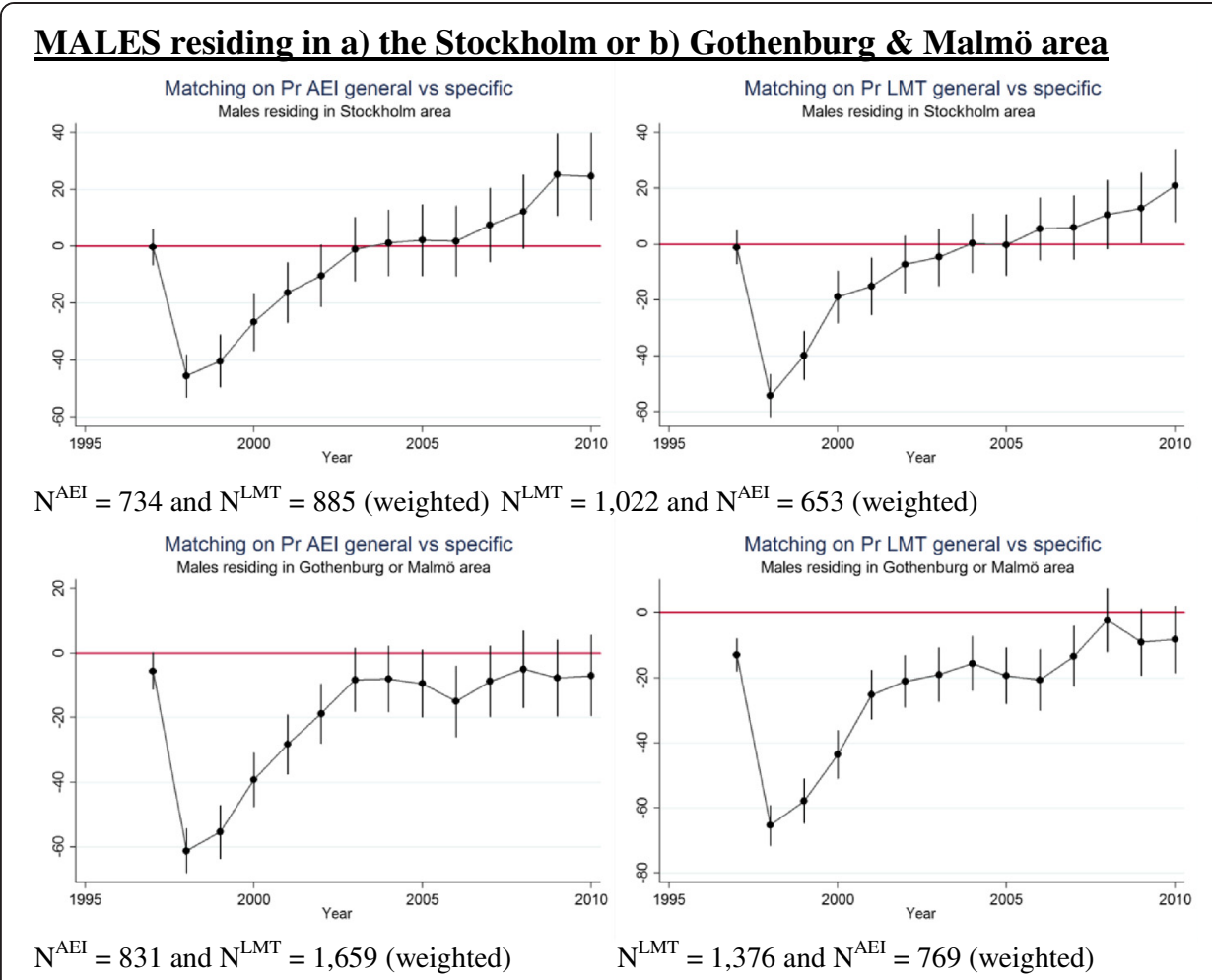

FEMALES residing in a) the Stockholm or b) Gothenburg \& Malmö area
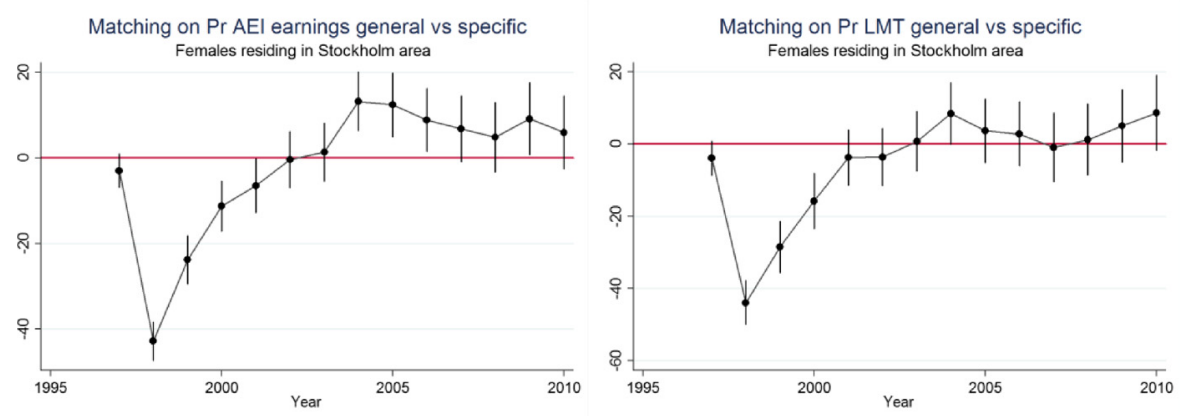

$\begin{aligned} \mathrm{N}^{\mathrm{AEI}}= & 1,396 \text { and } \mathrm{N}^{\mathrm{LMT}}=1,016 \text { (weighted) } \\ & \begin{array}{c}\text { Matching on } \mathrm{Pr} \text { AEI earnings general vs specific } \\ \text { Females residing in Gothenburg or Malmö area }\end{array}\end{aligned}$

$\mathrm{N}^{\mathrm{LMT}}=1,125$ and $\mathrm{N}^{\mathrm{AEI}}=1,551$ (weighted)
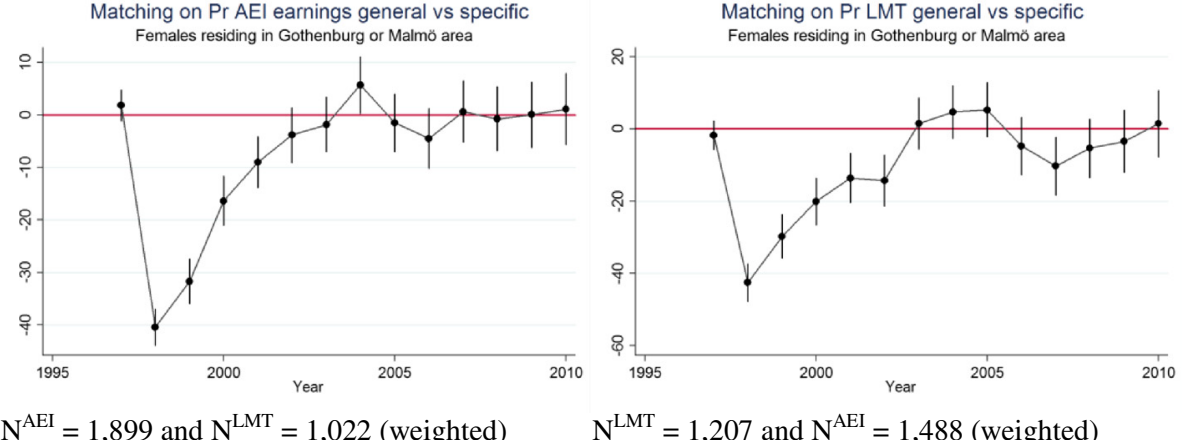

$\mathrm{N}^{\mathrm{AEI}}=1,899$ and $\mathrm{N}^{\mathrm{LMT}}=1,022$ (weighted)

$\mathrm{N}^{\mathrm{LMT}}=1,207$ and $\mathrm{N}^{\mathrm{AEI}}=1,488$ (weighted)

Fig. 7 Difference in differences matching, benchmark model estimates by area of residence

imply a recovery of initial losses around year 2020, whether one uses AEI or LMT as the "treatment" indicator. For program participants residing in Gothenburg or Malmö, the second and third largest regional labor markets in Sweden (in total around 750,000 
employed), the estimates are generally insignificant. The results are consistent with the idea that the relative program outcomes of different types of human capital are sensitive to local labor market characteristics, e.g. size, density, diversity and/or employment structure. The foremost difference in observable employment structures is that Stockholm has a lower share employed in the public sector and in manufacturing.

In Fig. 8, the estimation results are displayed for groups with 1) a two-year upper secondary school diploma and 2) no completion of upper secondary school. One could argue that groups with limited education are of particular interest because the AEI offers education at the levels that were not completed by the individuals in those groups. For males, there is a tendency for estimates to be above zero only in the case of no upper secondary school, but this does not hold when the matching is based on $\operatorname{Pr}[$ LMT $]$.

The results for females with prior completion of a two-year upper secondary program indicate positive relative earnings estimates of the AEI from 2003 to 2010, a result that also holds when the matching is based on $\operatorname{Pr}[\mathrm{LMT}]$. In both cases, the estimates imply that the initial relative earnings losses are recovered around 2020, but this does not hold when applying the extended model specification. Turning to females with no secondary education, at the bottom of Fig. 8 , the estimates are positive and statistically significant almost throughout from 2003 and onward, regardless of specification used. The accumulated net present values implied by the estimates indicate that the initial earnings disadvantage is already recovered within or just beyond our observation window. This result is very stable as it holds whether the matching is based on $\operatorname{Pr}[\mathrm{AEI}]$ or $\operatorname{Pr}[\mathrm{LMT}]$, and whether one employs the extended model specification. We also checked if the results reflect fertility decisions by conditioning on samples to have two children, most often signaling completed fertility, or to have zero children, but the overall implications remain robust. Thus, for this particular subgroup, expanding the menu of labor market programs to include general training appears associated with substantial efficiency gains.

While this last result seems relatively compelling, it may be difficult to generalize because 1997 was the first year of a reform. One could imagine that an inherent demand made individuals with the highest gains from the AEI more likely to enroll. To check this, we estimated the corresponding relative program effects for participants without upper secondary school in 1998, 1999, 2000 and 2001, using data of the same quality as described in Section 4. The business cycle recovered quickly in 1997-2000 and further contributed to generating a different composition of the samples. In six cases out of eight, these estimates imply a similar recovery of initial earnings losses of AEI. The exceptions are when employing $\operatorname{Pr}[\mathrm{LMT}]$ in the 1999 sample or the 2001 sample. We made a similar examination of the results for Stockholm residents, which hold only in five of 16 cases, with the $\operatorname{Pr}[\mathrm{AEI}]$ set-up for males in 2000 and 2001 and with both setups for females in 1998 and 2001.

Finally, we use the information contained in the test scores relating to cognitive and non-cognitive skills, which are available for males born 1953 or later. We separate this sample based on whether the respective test scores are above or below the median values, resulting in four groups in total (Fig. 9). The findings are now less precise but still display two clear patterns. First, dividing the sample based on cognitive skills, above or below the median, has little impact on estimates. Perhaps surprisingly, 


\section{MALES by schooling}
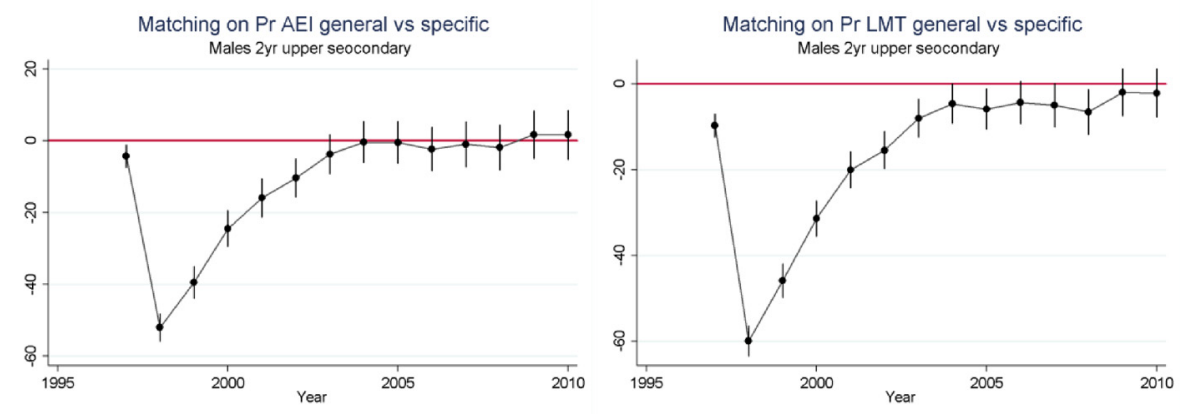

$\mathrm{N}^{\mathrm{AEI}}=2,534$ and $\mathrm{N}^{\mathrm{LMT}}=3,375$ (weighted) $\quad \mathrm{N}^{\mathrm{LMT}}=3,992$ and $\mathrm{N}^{\mathrm{AEI}}=2,432$ (weighted)
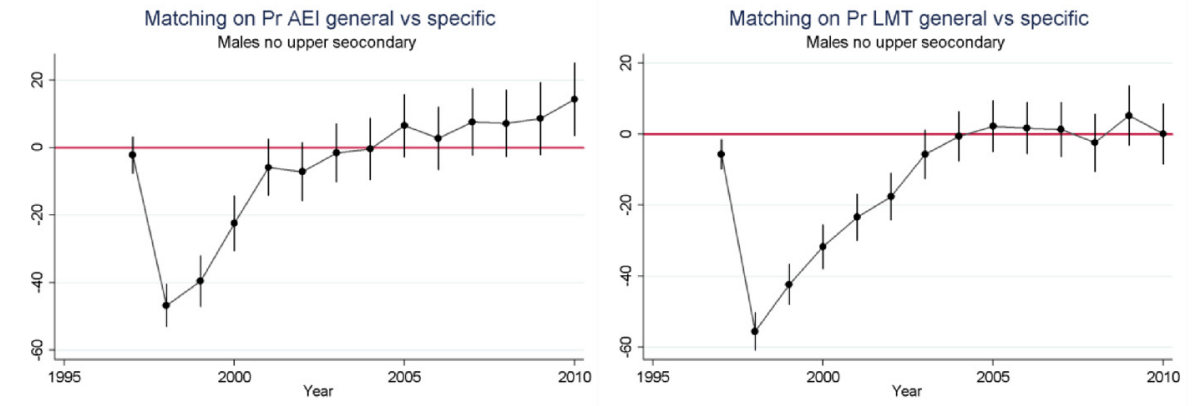

$\mathrm{N}^{\mathrm{AEI}}=978$ and $\mathrm{N}^{\mathrm{LMT}}=1,341$ (weighted)

$\mathrm{N}^{\mathrm{LMT}}=1,973$ and $\mathrm{N}^{\mathrm{AEI}}=970$ (weighted)

\section{FEMALES by schooling}
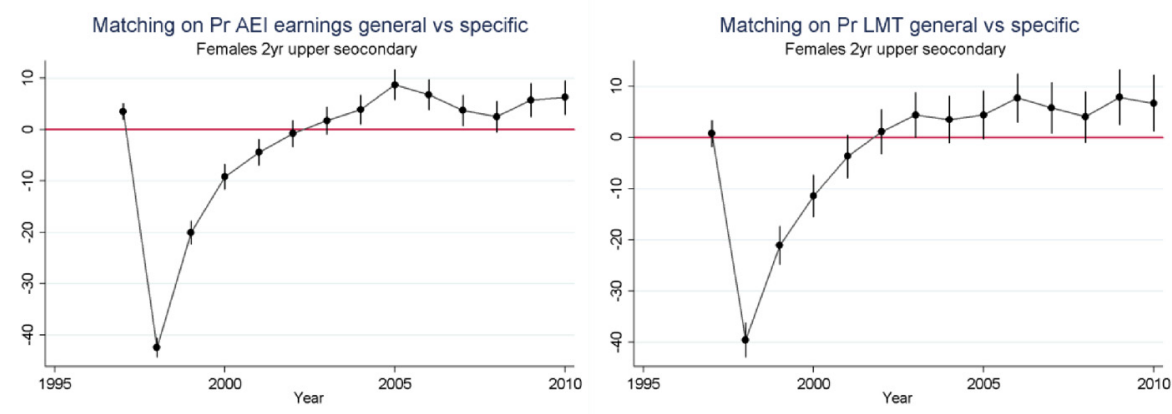

$\mathrm{N}^{\mathrm{AEI}}=7,340$ and $\mathrm{N}^{\mathrm{LMT}}=2,831$ (weighted)

$\mathrm{N}^{\mathrm{LMT}}=3,080$ and $\mathrm{N}^{\mathrm{AEI}}=5,207$ (weighted)
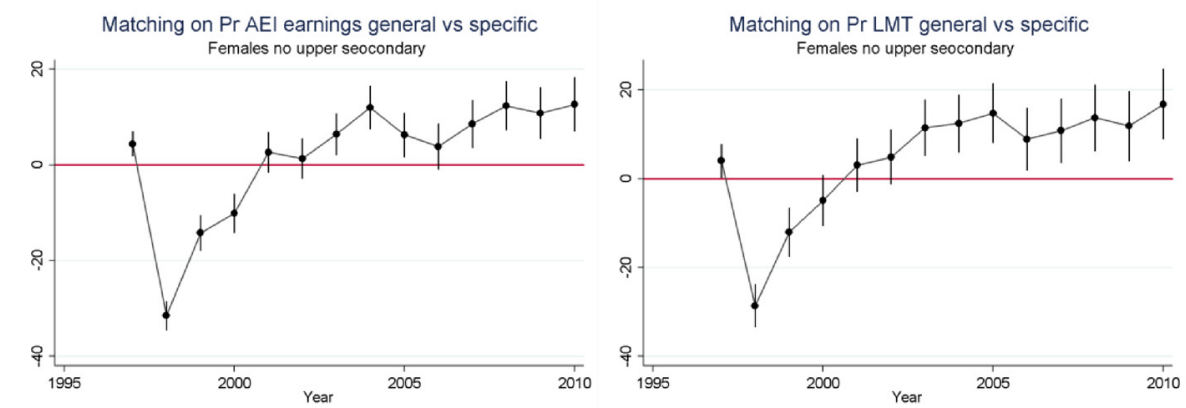

$\mathrm{N}^{\mathrm{AEI}}=2,625$ and $\mathrm{N}^{\mathrm{LMT}}=1,400$ (weighted)

$\mathrm{N}^{\mathrm{LMT}}=1,464$ and $\mathrm{N}^{\mathrm{AEI}}=2,051$ (weighted)

Fig. 8 Difference in differences matching, benchmark model estimates by prior level of education 


\section{MALES by cognitive skills}

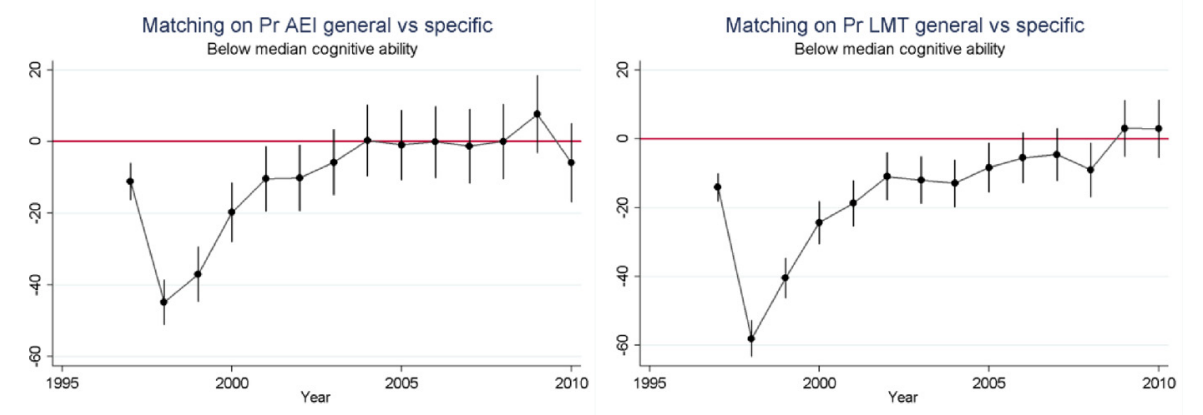

$\mathrm{N}^{\mathrm{AEI}}=987$ and $\mathrm{N}^{\mathrm{LMT}}=1,065$ (weighted) $\quad \mathrm{N}^{\mathrm{LMT}}=1,402$ and $\mathrm{N}^{\mathrm{AEI}}=763$ (weighted)
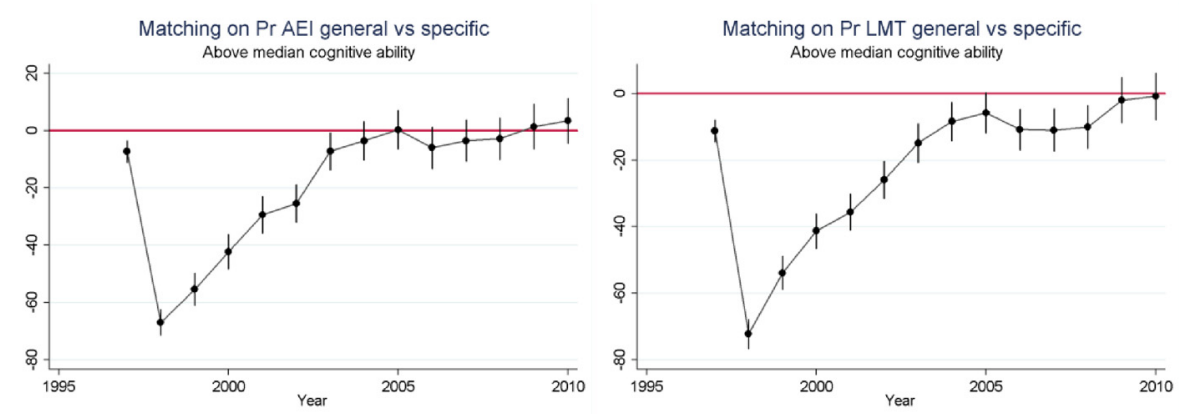

$\mathrm{N}^{\mathrm{AEI}}=1,795$ and $\mathrm{N}^{\mathrm{LMT}}=2,156$ (weighted) $\quad \mathrm{N}^{\mathrm{LMT}}=2,655$ and $\mathrm{N}^{\mathrm{AEI}}=1,653$ (weighted)

\section{MALES by non-cognitive skills}
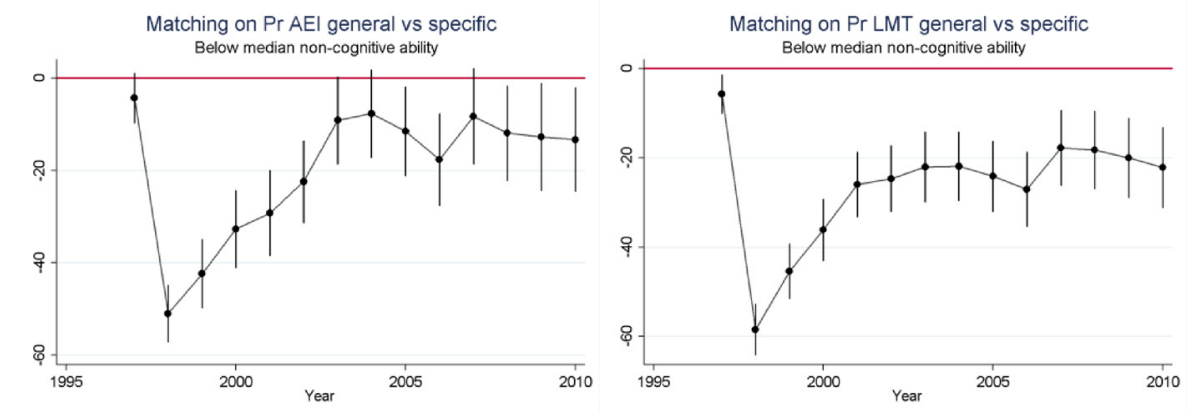

$\mathrm{N}^{\mathrm{AEI}}=839$ and $\mathrm{N}^{\mathrm{LMT}}=1,039$ (weighted) $\quad \mathrm{N}^{\mathrm{LMT}}=1,292$ and $\mathrm{N}^{\mathrm{AEI}}=803$ (weighted)
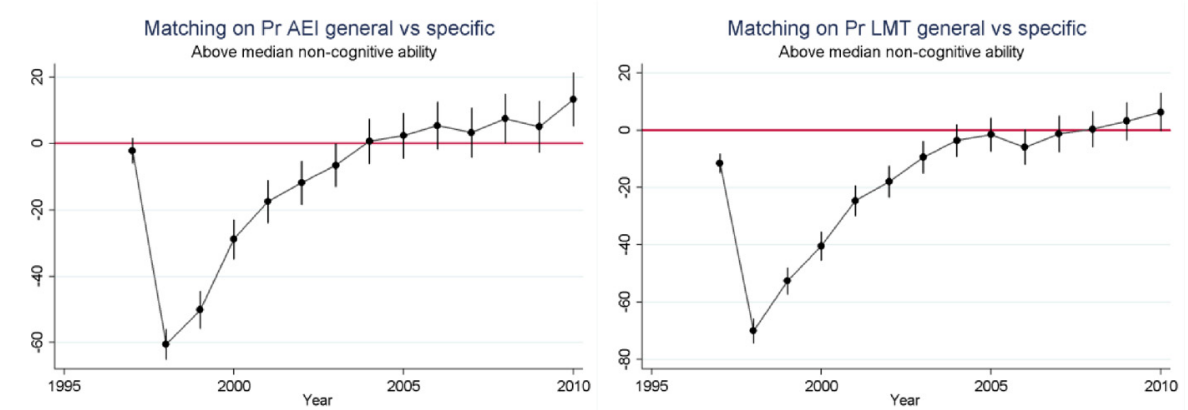

$\mathrm{N}^{\mathrm{AEI}}=1,736$ and $\mathrm{N}^{\mathrm{LMT}}=2,186$ (weighted)

$\mathrm{N}^{\mathrm{LMT}}=2,766$ and $\mathrm{N}^{\mathrm{AEI}}=1,624$ (weighted)

Fig. 9 Difference in differences matching, benchmark model estimates separately for above and below median of cognitive and non-cognitive skills 
cognitive skills do not seem to be important for the relative earnings impact of general vs. specific training. Second, the individuals with non-cognitive test scores below median appear to benefit more from specific training. For this group, the point estimates are statistically significant (negative) throughout. In contrast, those with above-median non-cognitive skills are associated with relatively stronger earning effects of general training. The magnitude of the positive estimates is overall modest (also with the limited sample or the extended model specification), but it is interesting that the pattern of results between the groups above and below median is relatively clear. A possible interpretation is that learning a specific skill is a way to compensate for a lower level of non-cognitive skills. Conversely, non-cognitive skills may be an important complement for benefiting from general training.

\section{Conclusions}

A principal contribution of this study is to provide empirical evidence on long term earnings associated with general training as an alternative to vocational/specific training. Heterogeneity among the unemployed, and in labor market demand for skills, implies that variety in the supply of training may allow individuals to capitalize on comparative advantages and improve the benefits of investments. With data on earnings 13 years post-enrolment showing differences between long-term and short-term outcomes, our analyses underscore the need for long follow-up periods to appropriately assess such programs. We also find strong indications that individuals tend to act on their comparative advantages. Characteristics predicting enrolment in general or specific training tend to be associated with estimated relative treatment effects that favor the chosen type of training. Methodologically, robustness checks for ability bias and time-varying characteristics prior to the program confirm our main findings.

For females with limited prior schooling and for participants in the metropolitan labor market of Stockholm, we find that general training is associated with earnings that exceed those of specific training. These findings are in line with the hypothesis that general training better enhances labor market prospects in the long run, by providing skills which make individuals less sensitive to labor market-related changes. Nevertheless, most of our estimates imply that vocational/specific training is associated with more favorable earnings trajectories. Therefore, arguments in favor of theoretical/general training programs must be based on the heterogeneity of the unemployed. As has been suggested earlier, theoretical programs may be especially appropriate in periods of high unemployment when opportunity costs are low and high numbers in specific training programs may inflict lower marginal returns.

Our study makes a distinct contribution compared with previous research, but there are some important caveats and we would like to point out four of these. First, the program costs are based on rough approximations and are assessed as equal on average. Second, the comparison between the two programs disregards outside alternatives, e.g., other programs. Third, other goals for policy (equity, democracy, etc.) are not considered. Fourth, general equilibrium effects are not considered. One might think here of costs associated with general training because, in the presence of labor market frictions, firms have incentives to offer not only specific training but also general education (Acemoglu and Pischke 1999). As in the case of specific training, increased public supply of 
general training may be associated with a deadweight loss due to crowding out of firms' investments in general skills.

\section{Endnotes}

${ }^{1}$ The results from evaluations of specific training for the unemployed in Sweden have differed across decades, with positive effects in the 1980s, zero or negative effects for participants at the start of the 1990s, and positive effects again in the late 1990s and early 2000s (e.g., Andrén and Gustafsson 2005, Calmfors et al. 2002, Axelsson and Westerlund 2005, Stenberg and Westerlund 2004, de Luna et al. 2008). The results at the start of the 1990s have usually been ascribed to the economic recession's effect on employment prospects and/or the large scale of labor market training programs at the time.

${ }^{2} \mathrm{~A}$ few studies compare the economic efficiency between other training programs, job search assistance, public employment, and/or wage subsidies (Lechner et al. 2011, Kluve 2010, Card et al. 2010; for Sweden, see Forslund et al. 2011 and Forslund et al. 2013).

${ }^{3}$ The average costs of the LMT would be SEK 33,300 [(141/360)*85000] compared with SEK 45,900 for the AEI if one assumes 1.35 years in Komvux on average. Our decision to disregard the differences is based on the fact that drop- outs complicate this calculation (completion rates at Komvux are below 60 percent), as does the fact that vocational programs vary greatly in their costs and we do not have access to information at the individual level. The implications of our estimates in the empirical section must be considered with this reservation about the costs in mind.

${ }^{4}$ About 14 percent of enrollees in AEI had completed at least a three-year upper secondary school program. As explained in Section 3, enrolment may be motivated by individuals' desires to redirect their studies or improve their grades. They may also have a diploma obtained in a foreign country.

${ }^{5}$ Cognitive skills are based on test scores of inductive, verbal, technical, and spatial skills. Non-cognitive scores are determined by a certified psychologist and measure social skills, leadership qualities, emotional stability and persistence. The scores are available for a subsample of 97,027 males born 1953 or later.

${ }^{6}$ In the case under study, assumption $i i$ can also be questioned because both training programs are large. However, Dahlberg and Forslund (2005) find no displacement effects of Swedish training programs in 1987-1996. One may note that they report substantial displacement effects of subsidized employment, as do Crépon et al. (2013) of job search assistance programs. Regarding positive externalities, Albrecht et al. (2009) argue that the returns to society of the AEI were higher than the individual earnings return by a factor of 1.5 .

${ }^{7}$ For some of the unemployed, program participation seems to be motivated primarily by avoidance of an active job search and/or to qualify for another period of UI benefits (Stenberg and Westerlund 2008, p63).

${ }^{8}$ For our extended model, the balancing concerns an additional 26 variables. We follow Heckman and Smith (1999) to control for nine different transitions in labor force status 1995-1996 between outside the labor force, employment and unemployment. Also included are levels 1996 and changes in the amounts of earnings and social 
insurance benefits in 1995-1996 and regarding sick-leave or social welfare also for 1996-1997 (we then assume that program choice does not cause transfers to change).

${ }^{9}$ See e.g. Chabé-Ferret 2015 for analysis and discussion on this matter.

${ }^{10}$ This is consistent with findings from studies assessing non-experimental estimates based on data of high quality. Card et al. (2010) conclude that "The absence of an 'experimental' effect suggests that the research designs used in recent non-experimental evaluations are not significantly biased relative to the benchmark of an experimental design" (F475, their quotation marks). Of course, this is not to say that adequate experimental data is not preferred. Nevertheless, when good non-experimental data is available, it is unreasonable to abstain from studying important research questions while waiting for the uncertain event of future access to relevant experimental data.

${ }^{11}$ Covariates are discarded from the probit estimates if $p$-values exceed .2, unless they are essential for the balancing of the samples (e.g., Caliendo and Kopeinig 2008, de Luna et al. 2011).

${ }^{12}$ Balancing the samples was at times difficult with one-to-one matching without "trimming" the samples (excluding treated participants). Therefore, the results presented are based on four-to-one matching, overall similar to the one-to-one matching estimates, but avoiding trimming. For the balancing tests, we set the threshold at $p$ values of .05. As we balance on more than 120 variables, we allowed one variable to be unbalanced by accident. Our checks indicate that this has no bearing on the estimated results.

${ }^{13} \mathrm{~A}$ conventional OLS estimator is perfectly symmetrical and switching between AEI and LMT indicators just switches the sign of the coefficient. The asymmetry in Figure 3 arises because, in the case where AEI is the treatment, matched LMT comparisons will to a greater extent be drawn from the side of the probability distribution where AEI participation is more likely. This is exacerbated by that matching is performed "with replacement" (to minimize bias). Thus, a matched comparison is always re-inserted ("replaced") into the pool of potential comparisons.

${ }^{14}$ The Probit estimates and the balancing tests behind the results in Fig. 4 are available on request.

${ }^{15}$ In Addiitional file 1: Table S6, we also present results from OLS regressions (1) without controls and (2) controlling for individual and year fixed effects. Compared with the OLS fixed effects, the full PSM model yields relative estimates which at the end of the observations window are slightly more to the advantage of LMT.

${ }^{16}$ We fully acknowledge that this may be developed, but leave it for future research. Our priority is to keep the discussion intelligible, and, because we are in relatively unexplored territory, to establish the qualitative results rather than to pin down the precise estimates.

${ }^{17}$ The magnitude of the loss for females in $1998-2002$ is about SEK 80,000 , only about half the amount for the males.

${ }^{18}$ The results obtained when conditioning samples on age, $25-42$ and $43-55$, and on whether annual earnings in 1995 were above or below median, did not differ in any important way from the overall results just presented. The working paper version of this article contains details on these analyses (Stenberg and Westerlund 2014). 


\section{Additional file}

Additional file 1: Table S1. Descriptive mean statistics by program. Table S2. Males, balancing tests, matched samples descriptive statistics. Two versions based on matching of probability estimates of AEI (left) or LMT (right). Table S3. Females, balancing tests, matched samples descriptive statistics. Two versions based on matching of probability estimates of AEI (left) or LMT (right). Table S4. Male OLS program estimates compared with "no program". Table S5. Female OLS program estimates compared with "no program". Table S6. OLS regression results, relative program effects. (DOC $336 \mathrm{~kb}$ )

\section{Competing interests}

The IZA Journal of European Labor Studies is committed to the IZA Guiding Principles of Research Integrity. The authors declare that they have observed these principles.

\section{Authors' information}

Anders Stenberg is Associate Professor of Economics at SOFI, Stockholm University. Olle Westerlund is Professor of Economics at the Department of Economics, Umeå University. Together they have during the last 15 years conducted research on formal education for adults and its impact on labor market outcomes.

\section{Acknowledgements}

We are grateful for valuable suggestions and comments on previous versions from Xavier de Luna, Anders Forslund, Helena Holmlund and seminar participants at IFAU, Uppsala, and the Workshop on Economics of Education at University of Barcelona. Financial support from IFAU, the Institute for Evaluation of Labour Market and Education Policy and from the Swedish Research Council (grant 2006-21576-36119-66) is gratefully acknowledged.

Responsible editor: Sara De la Rica.

\section{Author details}

${ }^{1}$ SOFI, Stockholm University, SE-10691 Stockholm, Sweden. ${ }^{2}$ Linneaus University, Växjö/Kalmar, Sweden. ${ }^{3}$ IZA, Bonn, Germany. ${ }^{4}$ Umeå School of Business and Economics, Umeå University, SE-901 87, Umeå, Sweden. ${ }^{5}$ CEDAR, Umeå Universtiy, Umeå, Sweden.

Received: 29 April 2015 Accepted: 30 October 2015

Published online: 13 November 2015

\section{References}

Acemoglu D, Pischke JS (1999) Beyond Becker. Training in Imperfect Labour Markets. Econ J 109(453):F112-F142

Albrecht JW, Van den Bergh G, Vroman SB (2009) The aggregate labour market effects of the Swedish Knowledge Lift program. Rev Econ Dyn 12(1):129-146

AMS (1999) Uppföljning av kursdeltagare som slutat yrkesinriktad arbetsmarknadsutbildning andra kvartalet 1998. Prora, Vol. 1

Andrén T, Gustafsson B (2005) Income effects from labour market training programs in Sweden During the 80s and 90s. Int J Manpow 25(8):688-713

Ashenfelter O (1978) Estimating the Effeect of Training Program son Earnings. Rev Econ Stat 60:47-57

Axelsson R, Westerlund O (2005) Kunskapslyftets effekter på årsarbetsinkomster - Nybörjare höstterminen 1997. Umeå Economic Studies, Vol. 647

Becker G (1964) Human Capital: A Theoretical and Empirical Analysis, with Special Reference to Education., NBER (3:e upplagan 1993)

Biewen M, Fitzenberger B, Osikominu A, Paul M (2014) The Effectiveness of Public-Sponsored Training Revisited: The Importance of Data and Methodological Choices. J Labor Econ 32(4):837-897

Brunello G (2003) On the Complementarity between Education and Training in Europe. In: Lucifora C (ed) Checchi, C. Education, Training and Labour Market Outcomes in Europe. MacMillan

Caliendo M, Kopeinig S (2008) Some Practical Guidance for the Implementation of Propensity Score Matching. J Econ Surv 22(1):31-72

Calmfors L, Forslund A, Hemström M (2002) Does Active Labor Market Policy Work? Lessons from the Swedish Experiences, IFAU Working Paper 2002., p 4, Uppsala

Card D, Kluve J, Weber A (2010) Active Labor Market Policy Evaluations: A Meta-Analysis. Econ J 120(548):F452-F477

Chabé-Ferret S (2015) Analysis of the Bias of Matching and Differene-in-Difference Under Alternative Earnings and Selection Processes. J Econ 185(1):110-123

Crépon B, Duflo E, Gurgand M, Rathelot R, Zamora P (2013) Do Labor Market Policies have Displacement Effects? Evidence from a Clustered Randomized Experiment. Q J Econ 128(2):531-580

Dahlberg M, Forslund A (2005) Direct Displacement Effects of Active Labor Market Programs. Scand J Econ 107(3):475-494

de Luna X, Forslund A, Liljeberg L (2008) Effekter av yrkesinriktad arbetsmarknadsutbildning för deltagare under perioden 2002-04, IFAU Rapport 2008., p 1, Uppsala

de Luna X, Waernbaum I, Richardson T (2011) Covariate Selection for the Non-Parametric Estimation of an Average Treatment Effect. Biometrika 98(4):861-875

Flores C, Flores-Lagunes A, Gonzalez A, Neumann T (2012) Estimating the Effects of Length of Exposure to Instruction in a Training Program: The Case of Job Corps. Rev Econ Stat 94(1):153-171

Forslund A, Fredriksson P, Vikström J (2011) What Active Labour Market Policy Works in a Recession? IFAU Working Paper 2011:2, Uppsala

Forslund A, Liljeberg L, von Trott zu Solz L (2013) Job Praftice: An Evaluation and a Comparison with Vocational Labour Market Market Training Programmes, IFAU Working Paper 2013., p 6, Uppsala 
Hanushek E, Woessman L, Zhang L (2011) General Education, Vocational Education, and Labor market Outcomes over the Life-Cycle. IZA discussion paper 6083

Heckman J, Smith J (1999) The Pre-Programme Earnings Dip and the Determinants of Participation in a Social Programme. Implications for Simple Programme Evaluation Strategies. Econ J 109:313-348

Heckman J, Urzua S (2008) The Option Value of Educational Choices and the Rate of Return to Educational Choices. University of Chicago, Mimeo

Heckman J, LaLonde R, Smith J (1999) The Economics and Econometrics of Active Labor Market Programs. In: Ashenfelter O, Card D (eds) Handbook of Labor Economic, Volume 3A, Ch. 31

Jacobson LS, LaLonde RJ, Sullivan DG (2003) Should We Teach Old Dogs New Tricks? The Impact of Community College Retraining on Older Displaced Workers. Federal Reserve Bank of Chicago WP 2003-25

Jacobson LS, LaLonde RJ, Sullivan DG (2005) The Returns to Community College Schooling for Displaced Workers. J Econ 25:271-304

Kluve J (2010) The Effectiveness of European Active Labour Market Programs. Labour Econ 17:904-918

Kluve J, Schneider H, Uhlendorff A, Zhong Z (2012) Evaluating Continuous Training Programmes by Using the Generalized Propensity Score. J R Stat Soc 175(2):587-617

Kreuger D, Kumar K (2004a) Skill-Specfic rather than General Education: A Reason for US-Europe Growth Differences? J Econ Growth 9:167-207

Kreuger D, Kumar K (2004b) US-Europe Differences in Technology-Driven Growth: Quantifying the role of Education. $J$ Monet Econ 51:161-190

Lechner M, Miquel R, Wunsch C (2011) Long-Run Effects of Public Sector Sponsored Training in West Germany. J Eur Econ Assoc 9(4):742-784

Pissarides C (2011) Regular Education as a Tool of Counter-Cyclical Employment Policy. Nordic Econ Policy Rev 1:207-232

Rosenbaum P, Rubin D (1983) The central role of the propensity score in observational studies for causal effects. Biometrika 70(1):41-55

Shavit Y, och Muller W (1998) From School to Work. Oxford University press, Cary, North Carolina.

Smith J, Todd P (2005) Does matching overcome LaLonde's critique of non-experimental estimators? J Econ 125(1-2):305-353

Stenberg A (2007) Comprehensive Education or Vocational Training for the Unemployed? Int J Manpow 28(1):42-61

Stenberg A (2011) Using Longitudinal Data to Evaluate Publicly Provided Formal Education for Low Skilled. Econ Educ $\operatorname{Rev} 30(6): 1262-1280$

Stenberg A, Westerlund O (2004) Does Comprehensive Education Work for the Long-term Unemployed? Umeå Economic Studies 641

Stenberg A, Westerlund O (2008) Does Comprehensive Education Work for the Unemployed? Labour Econ 15(1):54-67 Stenberg A, Westerlund O (2014) The Long Term Consequences of General vs. Specific Training for the Unemployed? IZA Discussion Paper 8668

Stenberg A, de Luna X, Westerlund O (2014) Does Formal Education for Older Workers Increase Earnings? Evidence Based on Rich Data and Long-term Follow-up. Labour 28(2):163-189

\section{Submit your manuscript to a SpringerOpen ${ }^{\circ}$ journal and benefit from:}

- Convenient online submission

- Rigorous peer review

- Immediate publication on acceptance

- Open access: articles freely available online

- High visibility within the field

- Retaining the copyright to your article 